\title{
Rapid assessment of food insecurity in the urban households in Karaj
}

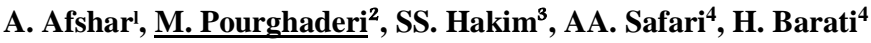

\footnotetext{
${ }^{1}$ Deputy of Food and Medicine, Alborz University of Medical Sciences, Karaj, Iran

${ }^{2}$ Faculty of Nutrition Sciences and Food Industry, Shahid Beheshti University of Medical Science, Tehran, Iran

${ }^{3}$ Alborz University of Medical Sciences, Karaj, Iran

${ }^{4}$ Central Staff, Alborz University of Medical Sciences, Karaj, Iran
}

Corresponding Address: Mona Pourghaderi, Department of Community Nutrition, Faculty of Nutrition Sciences and Food Industry, Shahid Beheshti University of Medical Sciences, Shahid Hafezi St., Shahid Farahzadi Blvd., Ghods Town (west), Tehran

Tel: +98-912-6090883; Email: pourghaderi2601@yahoo.com

Received: 19 Aug 2017; Accepted: 18 Nov 2017

\section{*bstract}

Background: Complex and multidimensional nature of measuring food insecurity has been an ongoing challenge for researchers.

Objective: The current study was conducted to assess household food insecurity in the city of Karaj, rapidly.

Methods: In this cross-sectional study, 677 households from different parts of Karaj were selected by the multi stage cluster sampling method. Information regarding dietary practices was also collected with semi quantified food frequency questionnaire. Food insecurity was assessed using Household Food Insecurity Access Scale (HFIAS). Consistency of research tools were estimated by Cronbach's alpha coefficient.

Findings: Totally, $76.6 \%$ households were food-insecure; with mild, moderate, and severe food insecurity $(47.2 \%, 21.3 \%$ and $8.1 \%)$ respectively. $16.8 \%$ of households often worried about inadequate food consumption by household members, and $18.3 \%$ were often unable to consume preferred food because of lack of resources. The secure and mild insecure food groups had significantly higher oil and meat consumption compared to the moderate and severe insecure group $(\mathrm{P}=0.04, \mathrm{P}=0.02$ respectively). Cronbach's alpha coefficient indicated the high internal consistency of the used questionnaire $(\alpha=0.89)$.

Conclusion: Food insecurity in household level has a high prevalence in the urban area of Karaj. Targeted and comprehensive policy actions with a combination of short and long term policies seem to be necessary to offset this problem.

Keywords: Food insecurity, Prevalence, HFIAS

Citation: Afshar A, Pourghaderi M, Hakim SS, Safari AA, Barati H. Rapid assessment of food insecurity in the urban households in Karaj. J Qazvin Univ Med Sci 2018; 22(2): 74-82. 


\title{
بررسى سريع نامنى غذايى در خانوارهاى ساكن شهر كرج
}

\author{
افشين افشار '، مونا يورقادرى'، سيده سارا حكيمّ"، دكتر علىاكبر صفرىعَ، دكتر حجتالله براتىع
}

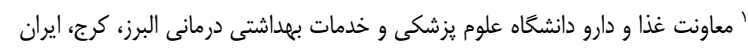

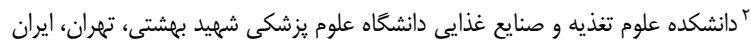

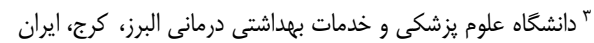

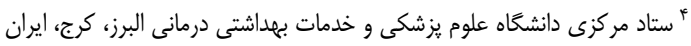

آدرس نويسنده مسؤول: تهران، شهرك قدس (غرب)، بلوار فرحزادى، خيابان شهيد حافظى، دانشكده علوم تغذيه و صنايع غذايى، دانشكاه علوم يزشكى شهيد بهشـى، كَروه تغذيـه

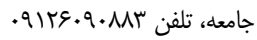
تايخ دريافت،

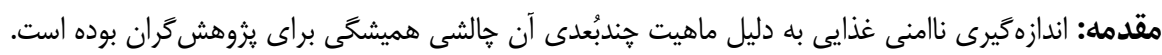

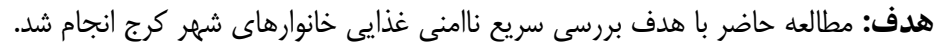

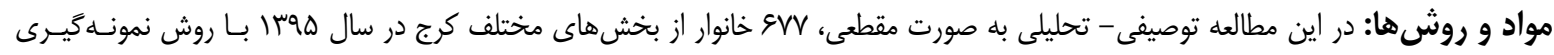

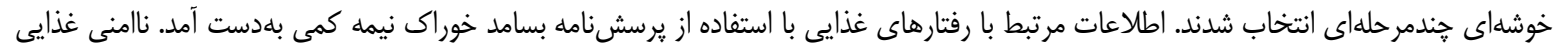

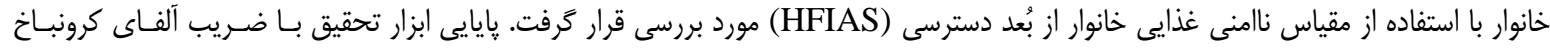

ارزيابى شد.

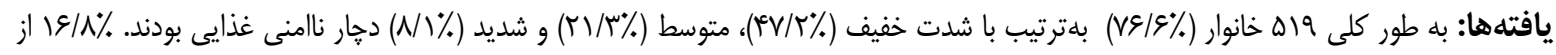

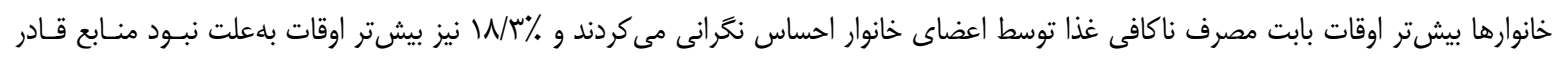

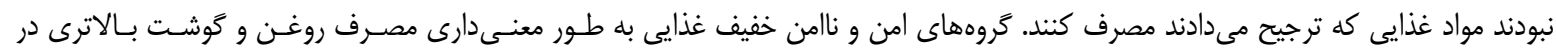

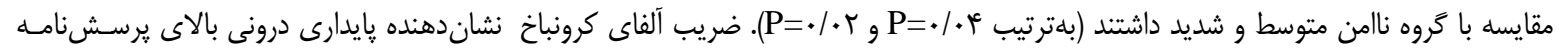

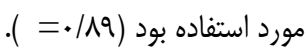

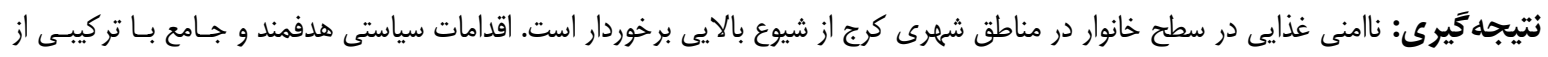

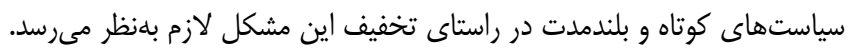

كليدوازهها: ناامنى غذايى، شيوع، HFIAS

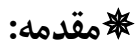

غذايى پايدار است.(r) در اين ميان گرسنگگى، تنها يكى از

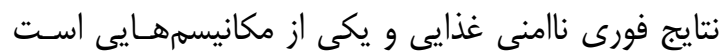

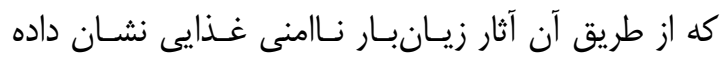

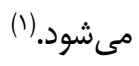
از آنجا كه امنيت غذايى بــه معنـى "دسترسـى همــــ

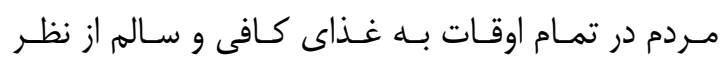
تغذيهاى و قابل قيذيرش توسط جامعه بـراى يـك زنـدگى

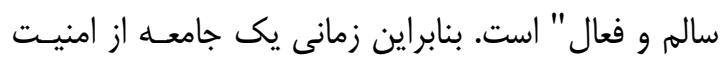

نامنى غذايى با مفهومى از بـىغـذايى و محروميـت از

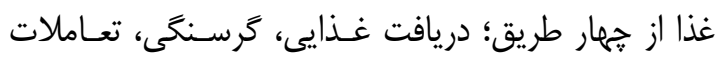

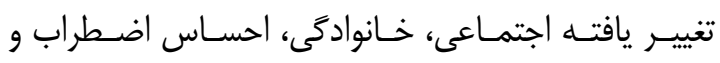

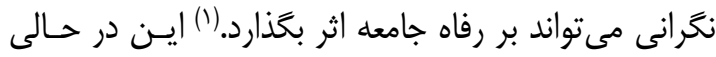
است كه امنيت غذايى بلهعنوان يكى از محورهاى توسعانه

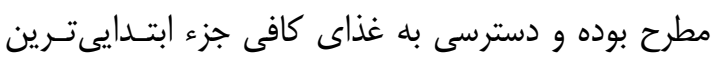

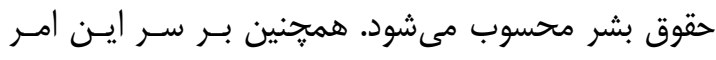

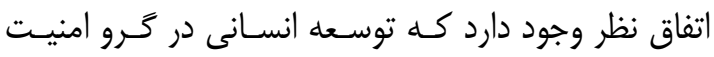


در • بر روز گَذشته تجربه كند بهعنوان نامن شديد غـذايى

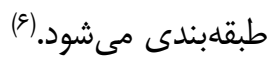

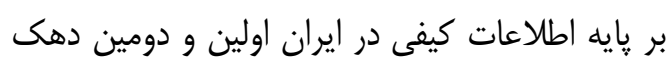

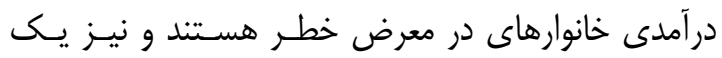
جهارم مردم ايران دجار كمبود انرزى و نيمى دهار كمبـود

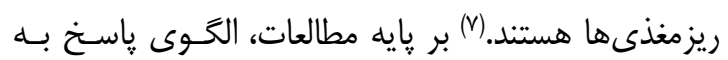
شرايط نامنى غذايى با اضطراب و نغرانى شروع و همـراه

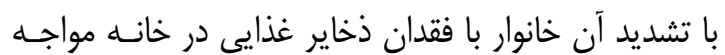

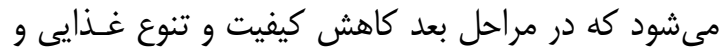

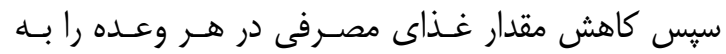

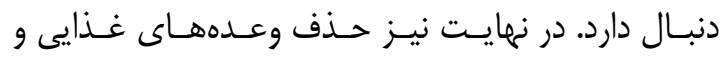

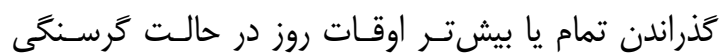
مورد انتظار است. (^) از طرفى در سال هاى اخيــر تعريـف و و

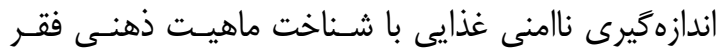

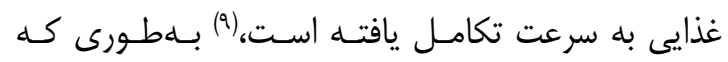

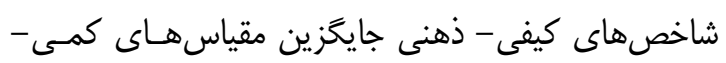

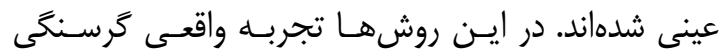

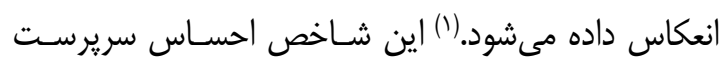

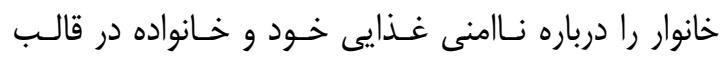

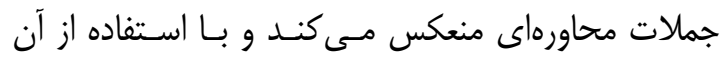

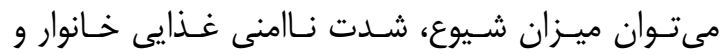
تغييرات آن رادر طول زمان نشان داد. اين مطالعه با هدف بررسى نامنى غذايى خانوار (از بُعد زمان

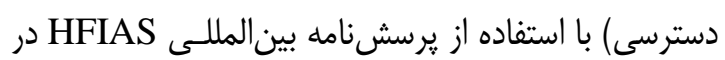
خانوارهاى شهرى كرج انجام شده است.

\section{مواد و روشها:}

اين مطالعه توصيفى - تحليلى بلهـورت مقطعى بـر

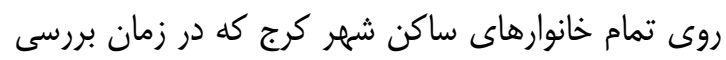

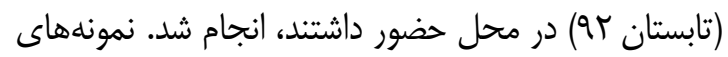

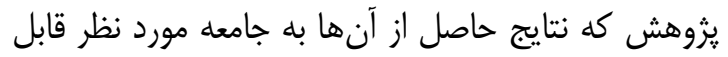

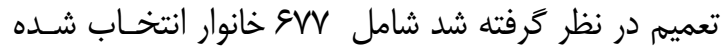
بودند كه براى انجام مصاحبه و تكميل فرمها با توجه بــهـ

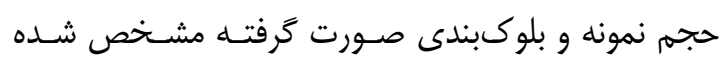

غذايى برخوردار است كه خطر عدم دسترسى اقتصـادى و

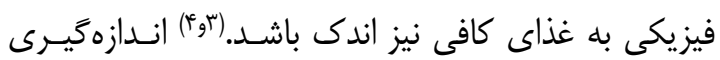

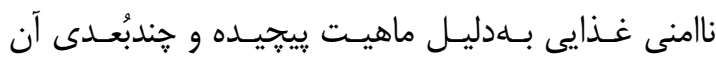

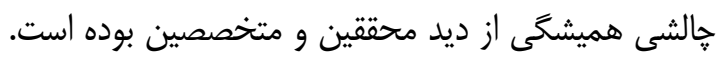

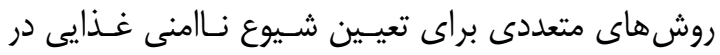

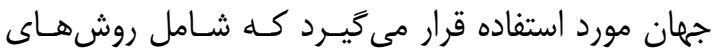

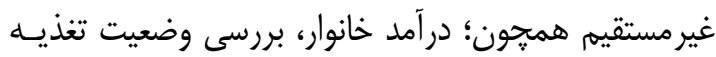

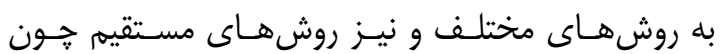

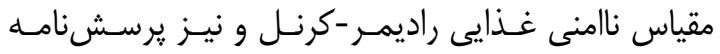

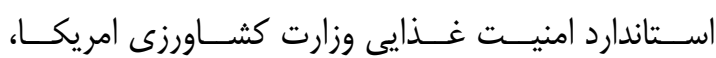
(Household food insecurity access scale, HFIAS)

(ه). (ه) يرسشنامه HFIAS بهعنوان ابـزارى سـريع، ارزان و مناسب طراحى و در مطالعات ميدانى مختلف استفاده شده

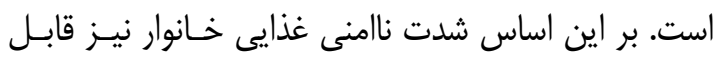

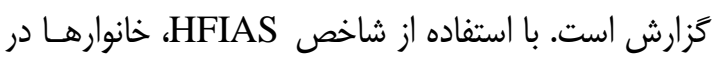
f سطح؛ امن غذايى، نامن خفيف، نامن متوسط و نـامن

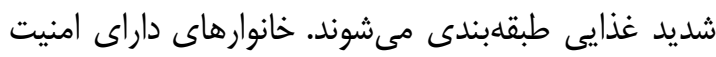

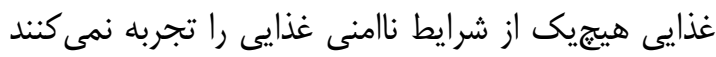

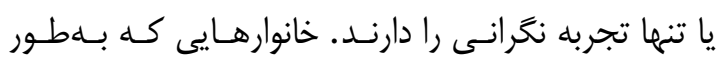
خفيف دجار نامنى غذايى هستند، بعضى يا بيشتر اوقـات

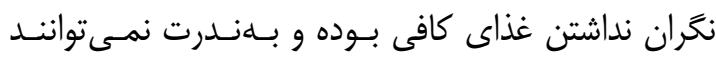

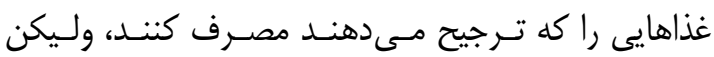

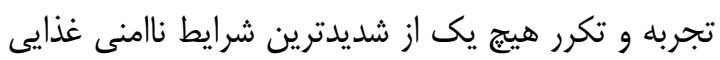

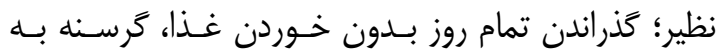
رختخواب رفتن و يا تمام شدن غذا را ندارنــــ خانوارهـاى دجار نامنى غذايى بلطور متوسط، بيشتر اوقات يك رزيم

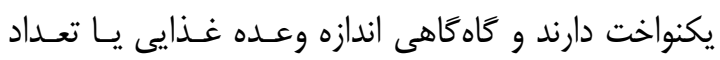

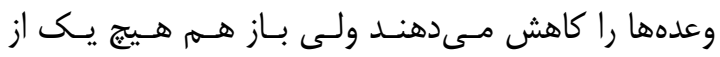
شديدترين شرايط را تجربه نمى كنند. خانوار دهـار نـامنى دهار

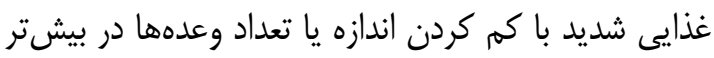

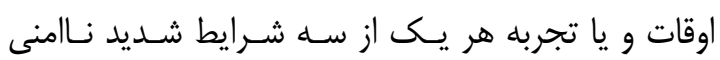
غذايى شناخته مىشوند. بلهعبارت ديخر هـر خـانوارى كـهـ هر يكى از سه شرايط شديد نامنى غذايى را حتى يكى بـار 
همجنين سطح تحصيلات اكثريـت سريرستان خـانوار در

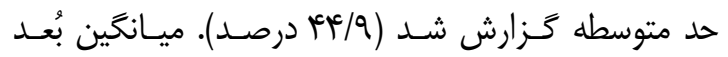

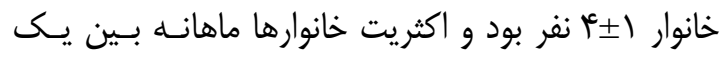

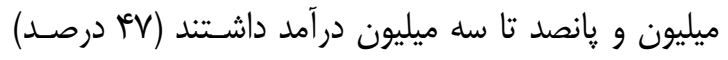
(جدول شماره ( ).

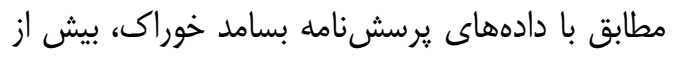
غذإ

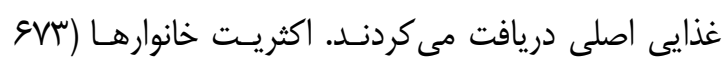

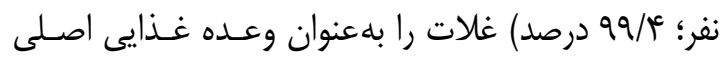

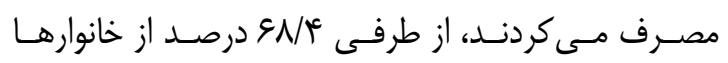

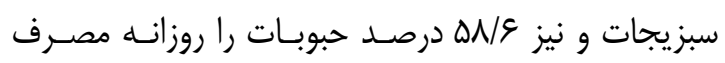
مى كردند.

جدول ا - ويزَّى هاى دموكَرافيك ياسخدهندكَان

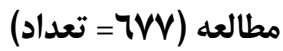

\begin{tabular}{|c|c|c|c|}
\hline درصد & تعداد & \multicolumn{2}{|c|}{ 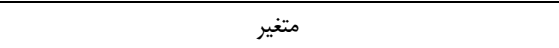 } \\
\hline r & T91 & \multirow{3}{*}{ 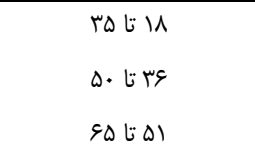 } & \multirow{3}{*}{ سن ياسخدهندكان } \\
\hline 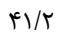 & TVq & & \\
\hline$T \cdot / T$ & rr| & & \\
\hline$F T / V$ & r/q & \multirow{3}{*}{ 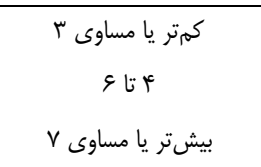 } & \multirow{3}{*}{ ت تعداد افراد خانوار } \\
\hline$\Delta \Delta / \tau$ & rVte & & \\
\hline$\cdot / \pi$ & 15 & & \\
\hline $9 V / 8$ & $i \Delta \Lambda$ & \multirow{2}{*}{ استيجارى } & \multirow{2}{*}{ ن نوع مسكن } \\
\hline$r T / F$ & 419 & & \\
\hline $1 \pi / r$ & $\wedge$ & \multirow{4}{*}{ 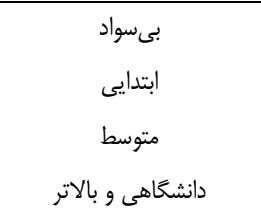 } & \multirow{4}{*}{ وضعيت سواد سريرست خانوار } \\
\hline $\mid N / 9$ & ITS & & \\
\hline$p+/ 9$ & $r \cdot r$ & & \\
\hline$T F / T$ & 195 & & \\
\hline $11 / 4$ & w & \multirow{5}{*}{ 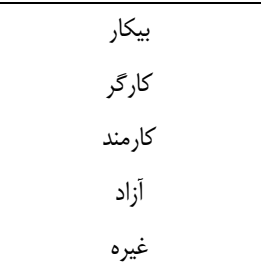 } & \multirow{5}{*}{ وضعيت شغلى سريرست خانوار } \\
\hline$r \cdot / \Lambda$ & $|F|$ & & \\
\hline$M / \Delta$ & זוץ & & \\
\hline V/Tr & $\mid \Delta F^{\circ}$ & & \\
\hline או & 94 & & \\
\hline$T F / T$ & let & \multirow{3}{*}{ 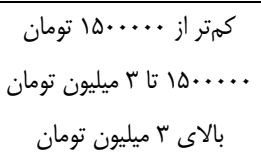 } & \multirow{3}{*}{ ميزان درآمد ماهانه خانوار } \\
\hline eV & MIN & & \\
\hline$\Gamma / / \Lambda$ & 190 & & \\
\hline
\end{tabular}

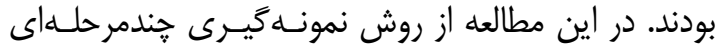

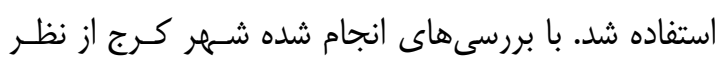

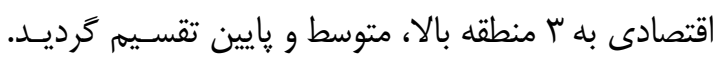

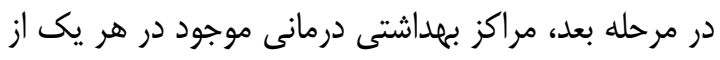

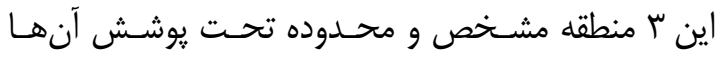

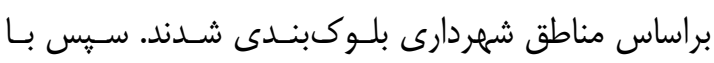

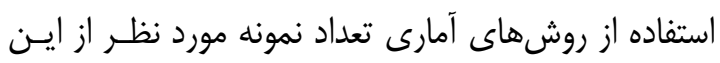

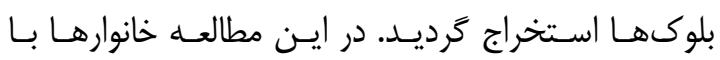

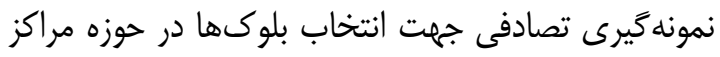

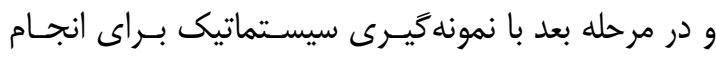
مصاحبه انتخاب شدند. براساس درصد شيوع نامنى در كشور كـهـ +r درصــ

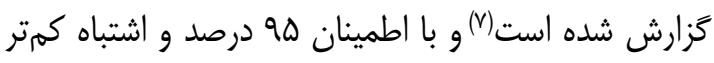

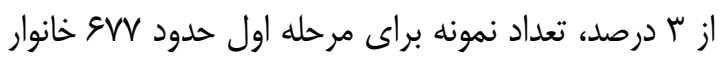

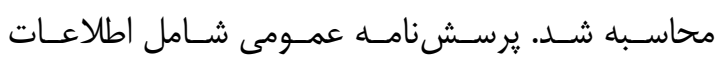

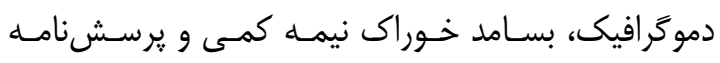
سنجش نامنى غذايى براى تمامى خانوارها تكميل ترديد.

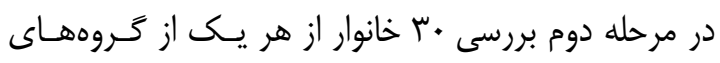

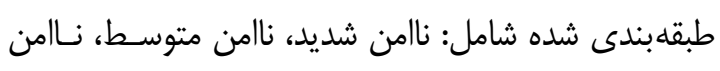

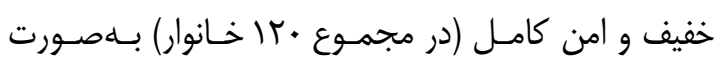

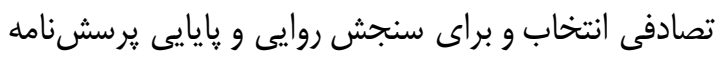

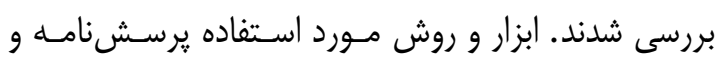

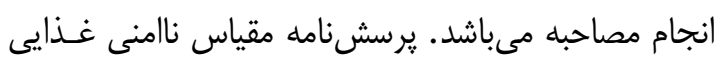

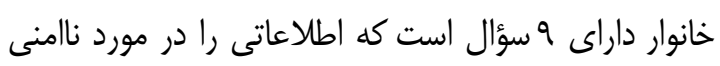

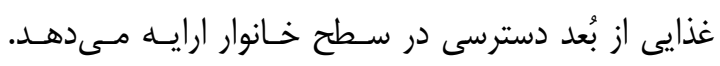

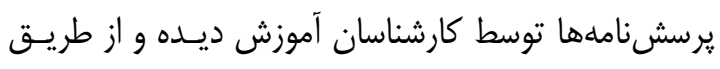

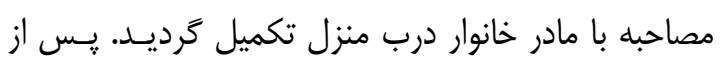

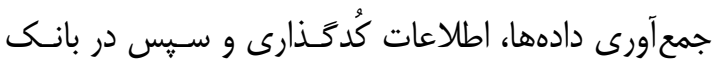

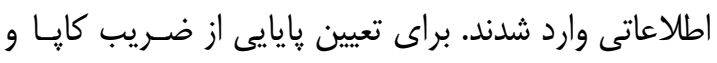
كندال و نرمافزار وا وان SPSS استفاده شد.

مت يافتهها:

متوسط سن קاسخخدهندكان

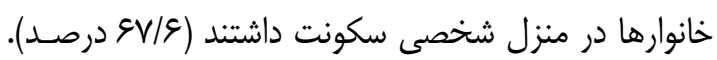


مى كردند كه واقعاً تمايلى به خوردنشان نداشـتند. تقريبـاً

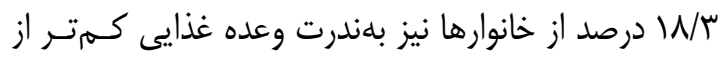

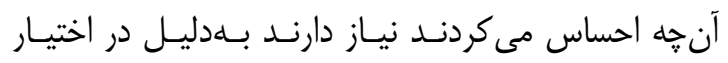
نداشتن غذاى كافى مصرف مى كردندا

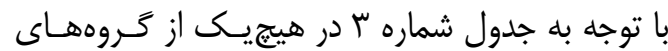

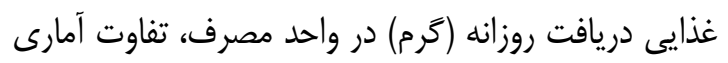

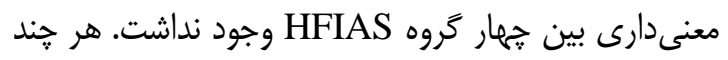

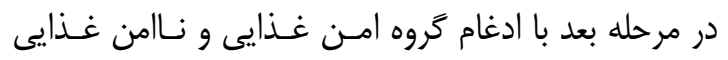
خفيف در يك طبقه و نيز نامن غذايى متوسط و شديد در

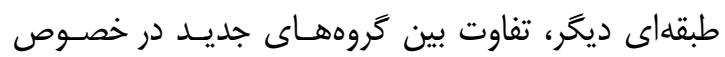

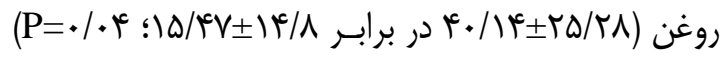

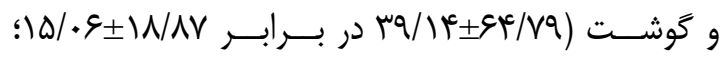

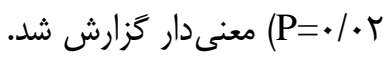

در مطالعه حاضـر، ه19 خـانوار (و/عV درصــد) نـامن

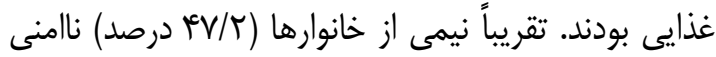

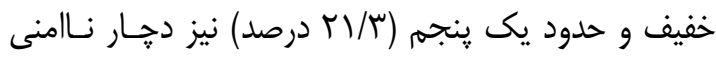

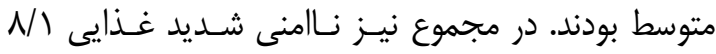

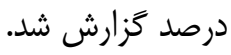

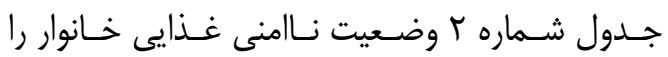

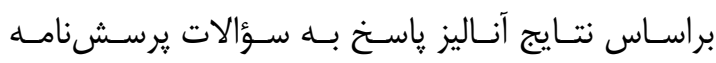
خان HFIAS

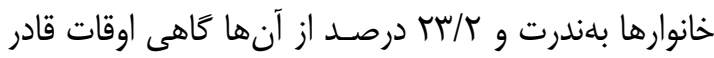

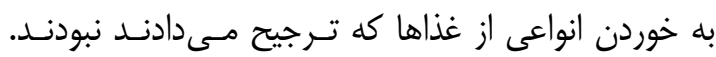

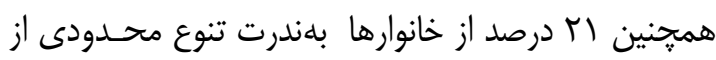

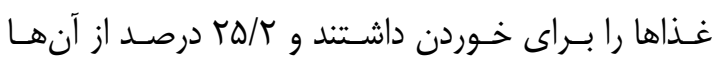

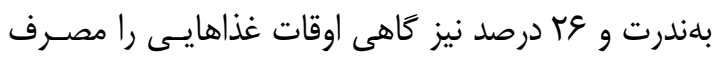

جدول r - شيوع نامنى غذايى بر پايه پِاسخ به سؤالات HFIAS در ميان خانوارهاى شهرى كرج

\begin{tabular}{|c|c|c|c|}
\hline بيشتر اوقات & كاهى اوقات & 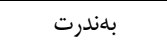 & \multirow{2}{*}{ سؤال } \\
\hline تعداد (درصد) & تعداد (درصد) & تعداد (درصد) & \\
\hline$x(\mid \varepsilon / \Lambda) 11 \%$ & $\operatorname{sx}(T Y) \backslash G$ & $x(1 . / 4) V$ & نغرانى از مصرف ناكافى غذا توسط اعضاى خانوار \\
\hline$x \times(\mid N / \mu) \mid K r^{2}$ & $\operatorname{sx}(r / T) \backslash Q V$ & $\operatorname{sx}(r \varepsilon / 0)$ IVq & عدم مصرف انواع غذاهايى كه ترجيح داده مىشود توسط اعضاى خانوار به خاطر نبودن منابع \\
\hline $\operatorname{xox}(\mathrm{V} / \Lambda) \Delta \mathrm{U}$ & $\operatorname{sox}(4 N / F) 194$ & $x(t) \mid F$ & مصرف انواع محدودى از غذاها توسط اعضاى خانوار به خاطر نبودن منابع \\
\hline $\operatorname{xox}(1 \cdot / 1) 91$ & $\operatorname{xox}($ Te) IVE & $x(T \Delta / T)|V|$ & مصرف غذايى كه اعضا خانوار دوست ندارند، به خاطر نبودن امكان تهيه غذاهاى ديخر \\
\hline $\operatorname{socox}(\% / l) \mathrm{rV}$ & $20 x(11) 90$ & $\operatorname{sox}(1 N / T) I K T^{2}$ & مصرف غذا كمتر از مقدارى كه اعضاى خانوار احساس مى كنند نياز دارند به خاطر نبودن غذاى كافى \\
\hline $\operatorname{sos}(r / \mathrm{V})$ ro & $\operatorname{sox}(N / \Delta) \Delta V$ & $\operatorname{sox}(\mid \xi / T) \|$ & كم كردن وعدههاى غذاى روزانه توسط اعضاى خانوار به خاطر نبودن غذاى كافى \\
\hline $\cos (T / M) / f$ & س r & $\operatorname{sos}_{(\Lambda / \mu)} \Delta S$ & عدم وجود غذاى كافى در منزل به خاطر نبودن منبعى براى تهيه غذا ع \\
\hline $\operatorname{sos}(1 / \Lambda) i t$ & $\cos (Y / V) \backslash \Lambda$ & $\cos (\mu / I) M$ & كر سنه خوابيدن اعضاى خانوار به خاطر نبودن غذاى كافى \\
\hline $\operatorname{xoc}(\cdot / \mathrm{V})^{\mathrm{F}}$ & $\cos (\cdot / \Lambda) \Delta$ & $\cos (\mathrm{I} / \mathrm{V}) \mathrm{Ir}$ & كذراندن تمام روز بدون اين كه اعضاى خانوار خيزى خورده باشند، به خاطر نبودن غذاى كافى \\
\hline
\end{tabular}

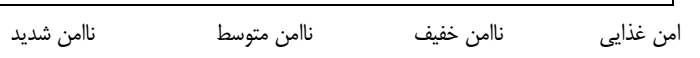

جدول ب- دريافت غذايى در واحد مصرف برحسب طبقلبندى HFIAS

\begin{tabular}{|c|c|c|c|c|c|c|c|c|}
\hline \multicolumn{8}{|c|}{ مصرف غذا در واحد مصرف (كرم/ روز) ميانكين 土 انحراف معيار } & \multirow{2}{*}{ طبقه HFIAS } \\
\hline 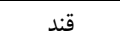 & 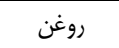 & 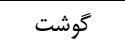 & شير & سبزيجات & ميوه & 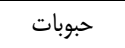 & 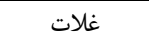 & \\
\hline$V / \kappa+ \pm \Lambda / r$. & $T / R V \pm \Delta / T H$ & $r / \Psi \wedge \pm \varepsilon / V T$ & $V / I V Y \pm Y / I T V$ & 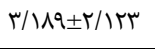 & $r / \Delta \Lambda \pm \Lambda / r T$ & G/KTED/TV & $T / \mu \cdot \Delta \pm T / N F$ & 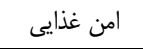 \\
\hline$T / K+r / T \Lambda$ & $\Gamma / \Gamma \Lambda \pm \Lambda / T V$ & $\Delta / r F \pm \Delta / q T$ & $\Delta / \lambda \Lambda F^{\prime} \pm V / / H T$ & $V / T \cdot F \pm g / I T \Delta$ & $G / \& Y \pm \Delta / \& \mid$ & $V / f \cdot \pm r / r V$ & $\Delta / r q \Psi \pm \varepsilon / 11 \Lambda$ & نامن خفيف \\
\hline$\varepsilon / Y \Lambda \pm g / \Delta)$ & $T / / Y \pm \Delta / / F$ & $r / / V \pm \psi / 19$ & $r / / r q \pm N / I / V$ & $9 / 11 \cdot \pm 9 / / r r$ & $g / \Delta r \pm q / \varepsilon$. & 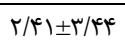 & $\Delta / r \wedge q \pm T / / T \&$ & نامن متوسط \\
\hline$N / 4 I \pm R / M I$ & $r / / f \pm V / \backslash \varphi$ & $N / \mid r \pm V / T I$ & $r / / r s \pm r / / F \Delta$ & 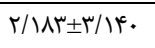 & $V / \uparrow \wedge \pm \Gamma / \mathcal{G} \Gamma$ & $r / r \Lambda \pm r / r \Delta$ & G/ $/ \Gamma \pm \Gamma / \Lambda \Lambda \Delta$ & نامن شديد \\
\hline
\end{tabular}


مقايسه با مطالعهاى در مالاوى كمتر مى باشد.(1M-r(M)

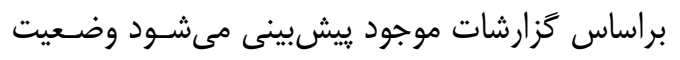

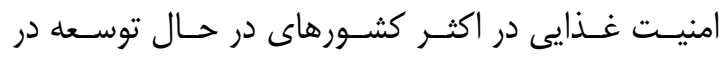

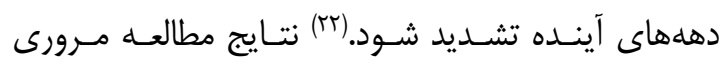

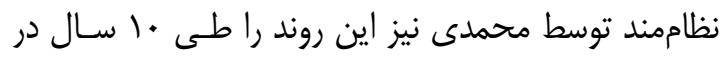
خصوص نامنى خفيف و متوسط داراى سير صعودى نشان مى دهد هرجند كه از نظر آمارى معنى دار نبود.

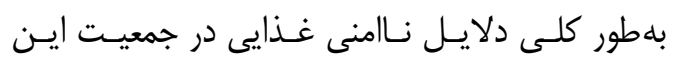

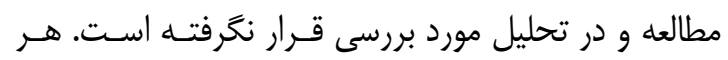

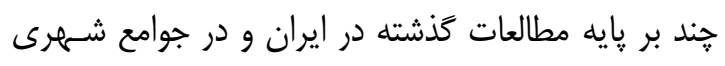

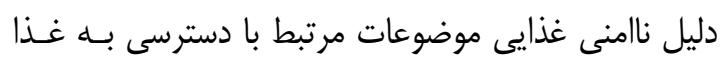

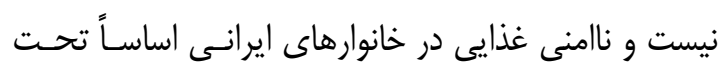

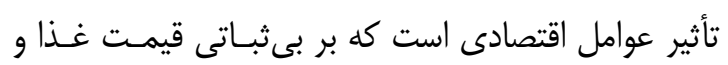

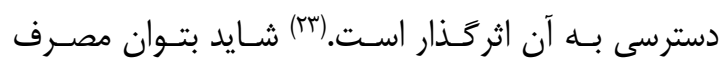
بيشتر اقلام غذايى در گروه غاتلات و نيز كـاهش آشـكار

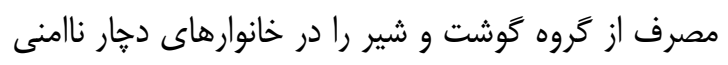
غذايى به اين موضوع نسبت داد.

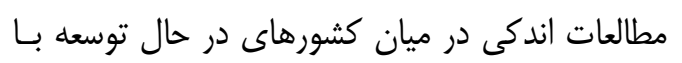

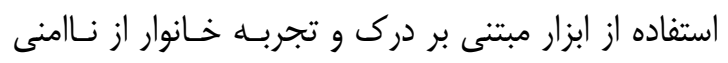

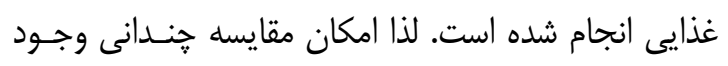

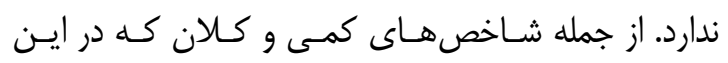
خصوص موجود است مىتوان به؛ توليد سرانه غذا، ميـزان

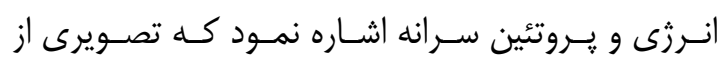
دستر سى واقعى در خانوار ارايه نمى كند.

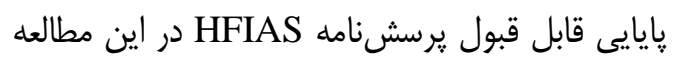

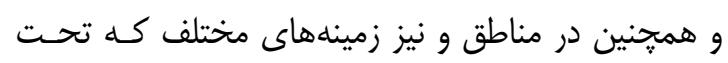

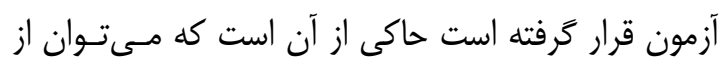

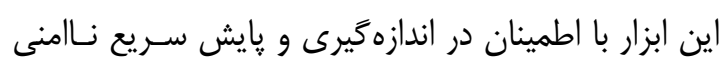

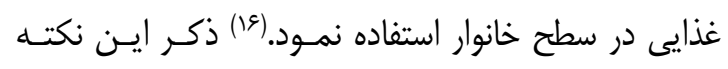

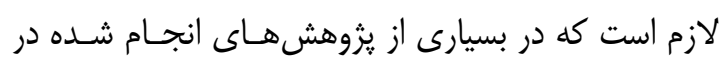

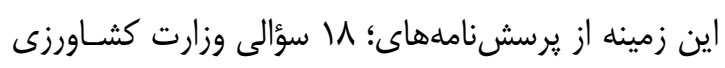

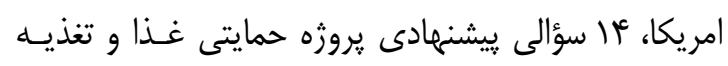

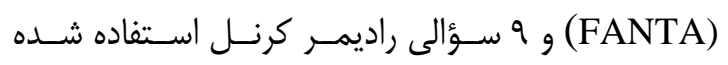

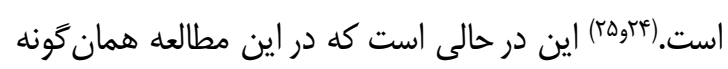

از نظر شاخصهاى اقتصـادى، بـين سـطح درآمــد در

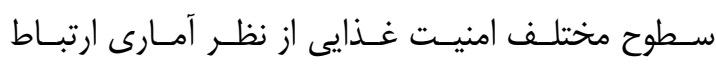

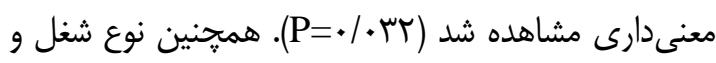

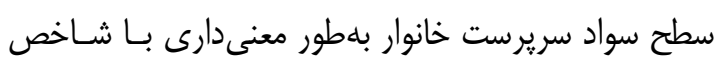

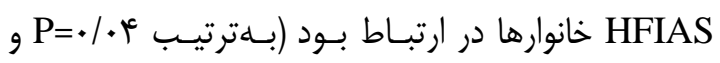

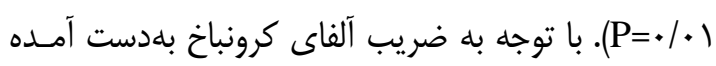

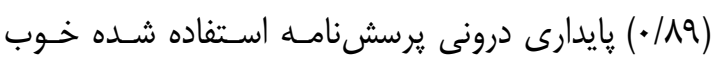
برآورد مىشود.

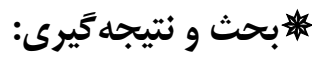

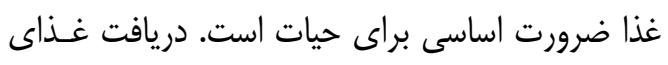

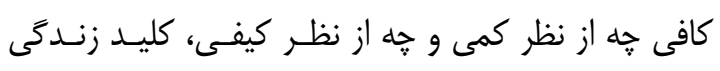

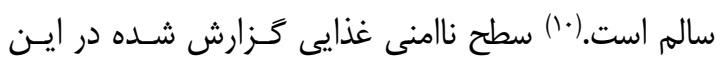

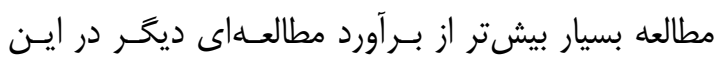

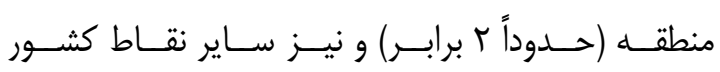

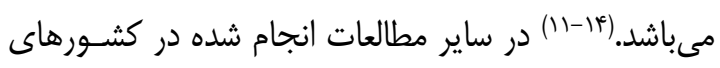

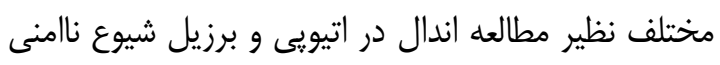

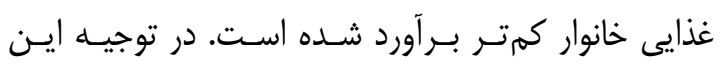

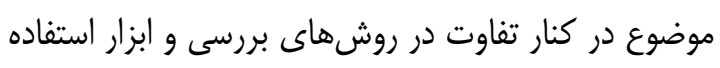

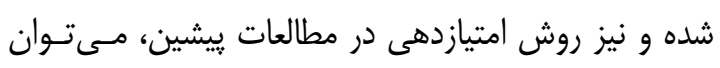

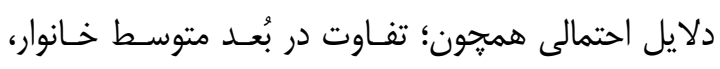
تعداد افراد شاغل در خانوار و درآمد ماهيانه خانوار را مـؤثرث

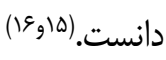
محمدى و همكـاران در قالـب يــ مطالعـه مـرورى

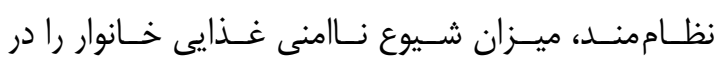

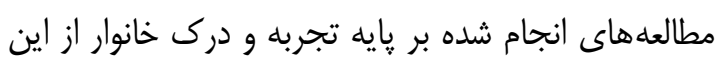

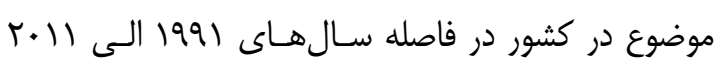

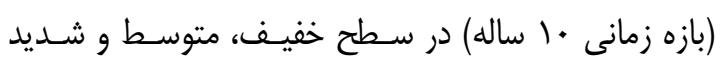

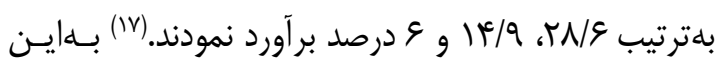

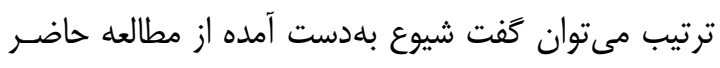

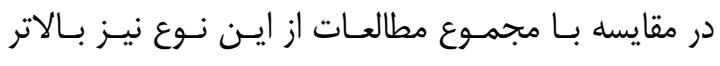

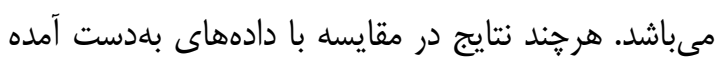

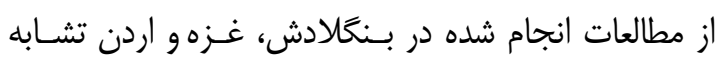

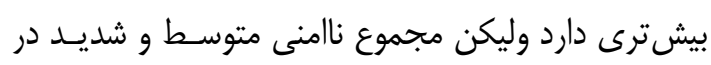




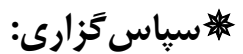

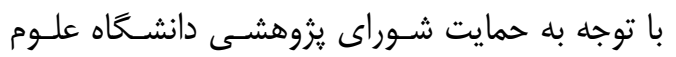

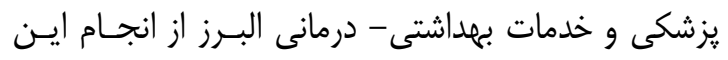

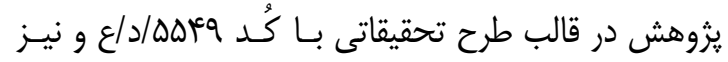

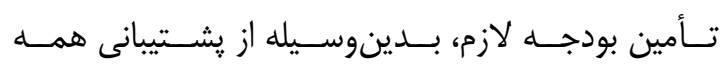
دستاندركاران و نيز معاونت آموزشى و يزوهشى دانشـانهاه قدردانى مى تردد.

\section{: مراجع:}

1. Bazerghi C, Mckay FH, Dunn M. The role of food banks in addressing food insecurity: a systematic review. J Community Health 2016; 41(4): 732-40. doi: 10.1007/s10900015-0147-5.

2. Shakoori A. Food security and access to it in Iran. J Social Science Letter 2004; 24(24): 133-60 [In Persian].

3. Fox AM, Balarajan Y, Cheng C, Reich MR. Measuring political commitment and opportunities to advance food and nutrition security: piloting a rapid assessment tool. Health Policy Plan 2015; 30 (5): 566-78. doi: 10.1093/heapol/czu035.

4. Derrickson JP, Fisher AG, Anderson JE, Brown AC. An assessment of various household food security measures in Hawaiı ${ }^{*}$ has implications for national food security research and monitoring. J Nutr 2001; 131(3): 749-57.

5. Ashby S, Kleve S, McKechnie R, Palermo C. Measurement of the dimensions of food insecurity in developed countries: a systematic literature review. Public Health Nutr 2016; 19(16): 2887-96.

6. Knueppel D, Demment M, Kaiser L. Validation of the household food insecurity access scale in rural Tanzania. Public Health Nutr 2010; 13(3): 360-7. doi: 10.1017/ S1368980009991121.
كه در روش كار به آن اشاره شد از يرسشنامـه 9 سـؤالى HFIAS

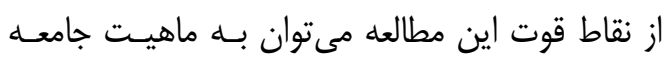

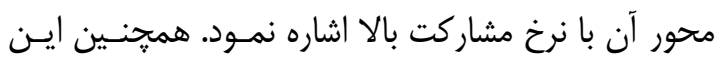

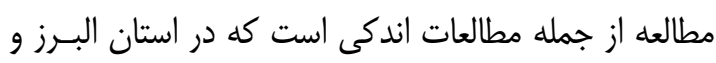

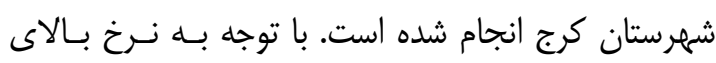

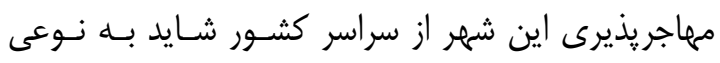

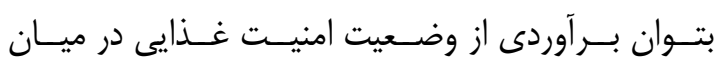

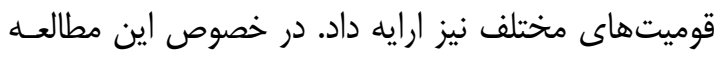

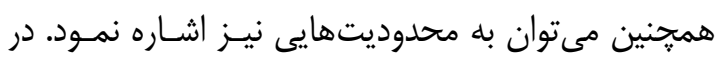

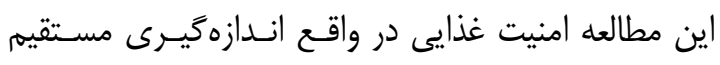

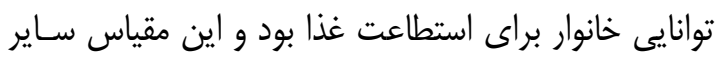

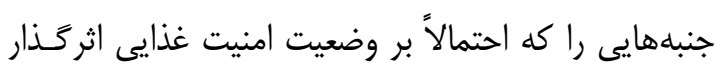
است نظير تبعسيض جنسـيتى در تخصـيص غـذا، كيفيــات

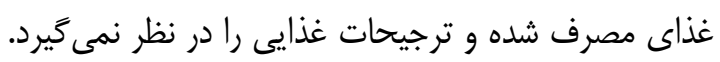

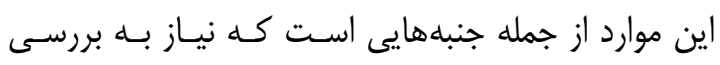

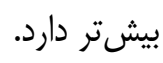
مطالعه حاضر نشان داد، در مناطق شهرى كرج شيوع

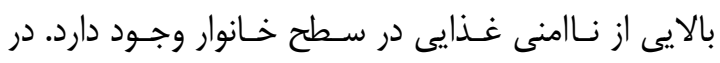

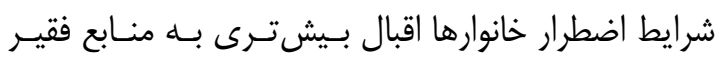

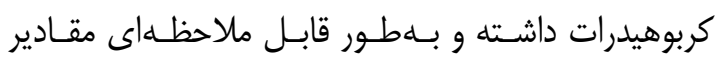

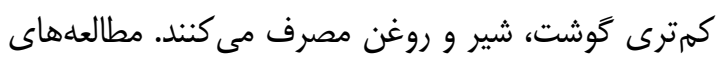

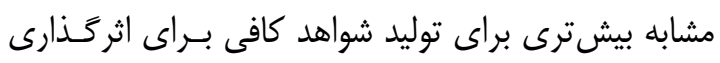

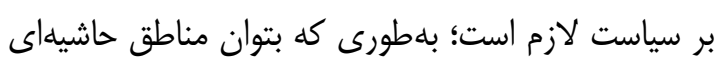

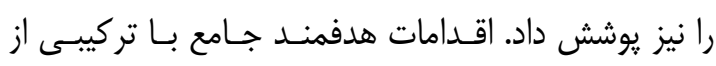

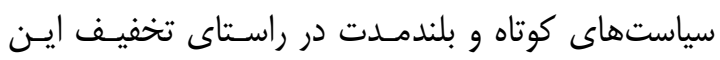

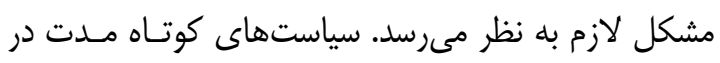

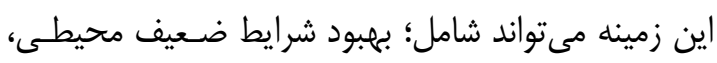

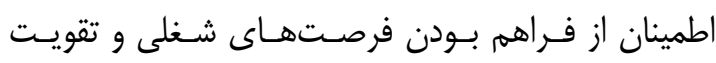

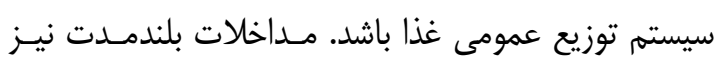

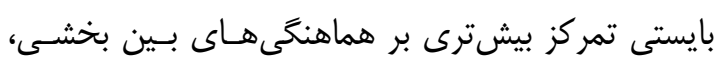

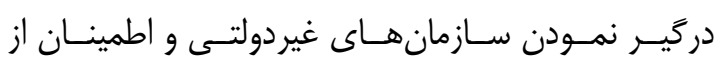
توانمندسازى زنان داشته باشد. 
7. Ghasemi H. Food and nutrition security in Iran: a national study on planning and administration. Tehran: Plan and Budget Organization; 1998. [In Persian].

8. Ganapathy S, Duffy SB, Getz C. A framework for understanding food insecurity: an anti-hunger approach, a food systems approach. Berkeley, CA: UC center for weight and health 2005. 114.

9. Interlenghi GS, Reichenheim ME, SegallCorrêa AM, Pérez-Escamilla R, Moraes CL, Salles-Costa R. Modeling optimal cutoffs for the Brazilian household food insecurity measurement scale in a nationwide representative sample. J Nutr 2017; 147(7): 1356-65. doi: 10.3945/jn.117.249581.

10. Becquey E, Martin-Prevel Y, Traissac P, Dembélé B, Bambara A, Delpeuch F. The household food insecurity access scale and an index-member dietary diversity score contribute valid and complementary information on household food insecurity in an urban West-African setting. J Nutr 2010; 140(12): 2233-40. doi: 10.3945/jn.110. 125716.

11. Kian F, Farhadian H, Chobchian SH. Food insecurity assess of urban household of Alborz province. Food Science and Technology 2015; 13(55): 167-79. [In Persian].

12. Dorosty AR, Karamsoltani Z, Jazayeri A, Siassi F, Eshraghian MR. Association between obesity, food security and related family factors. J Sch Public Health Inst Public Health Res 2008; 6(1): 1-9 [In Persian].

13. Rafiei M, Nord M, Sadeghizadeh A, Entezari MH. Assessing the internal validity of a household survey-based food security measure adapted for use in Iran. Nutr J 2009; 8: 28. doi: 10.1186/1475-2891-8-28.

14. Mohammadi F, Omidvar N, Houshiar-
Rad A, Khoshfetrat MR, Abdollahi M, Mehrabi Y. Validity of an adapted household food insecurity access scale in urban households in Iran. Public Health Nutr 2012; 15(1): $\quad 149-57 . \quad$ doi: $10.1017 /$ S1368980011001376.

15. Endale W, Mengesha ZB, Atinafu A, Adane AA. Food insecurity in Farta district, northwest Ethiopia: a community based cross-sectional study. BMC Res Notes 2014, 7: 130. doi: 10.1186/1756-0500-7-130.

16. Facchini LA, Nunes BP, Motta JV, Tomasi E, Silva SM, Thumé E, et al. Food insecurity in the Northeast and South of Brazil: magnitude, associated factors, and per capita income patterns for reducing inequities. Cad Saude Publica 2014; 30(1): 161-74. doi: 10.1590/0102-311X00036013.

17. Mohammadi-Nasrabadi F, Omidvar N, Khoshfetrat MR, Kolahdooz F. Household food insecurity in the Islamic Republic of Iran: a systematic review and meta-analysis. East Mediterr Health J 2014; 20(11): 698706.

18. Farzana FD, Rahman AS, Sultana S, Raihan MJ, Haque MA, Waid JL, et al. Coping strategies related to food insecurity at the household level in Bangladesh. PLoS One 2017; 12(4): 1-17. doi: 10.1371/journal.pone. 0171411.

19. Ziadni M, Hammoudeh W, Rmeileh NM, Hogan D, Shannon H, Giacaman R. Sources of human insecurity in post-war situations: The case of Gaza. J Hum Secur 2011; 7(3): 1-16. doi: 10.3316/JHS0703023.

20. Bawadi HA, Tayyem RF, Dwairy AN, Al-Akour N. Prevalence of food insecurity among women in northern Jordan. J Health Popul Nutr 2012; 30(1): 49-55.

21. Deitchler M, Ballard T, Swindale A, Coates J. Introducing a simple measure of 
household hunger for cross-cultural use. Available at: http://www.fao.org/fileadmin/ user_upload/wa_workshop/docs/HH_Hunger_ Scale.pdf. Updated in: 2011.

22. Ghasemi H, Kimiagar M, Koupahi M. Food nutrition security in Tehran province. Tehran: National Nutrition and Food Tecnology Research Institute; 1996 [In Persian].

23. Mohammadi-Nasrabadi F. Measurement and modeling of household food security in urban households in the city of Tehran. PhD Thesis, Faculty of Nutrition Sciences and Food Technology, Shahid Beheshti
University of Medical Sciences; 2011 [In Persian].

24. Ihabi AN, Rohana AJ, Wan Manan WM, Wan Suriati WN, Zalilah MS, Rusli AM. Nutritional outcomes related to household food insecurity among mothers in rural Malaysia. J Health Popul Nutr 2013; 31(4): 480-9.

25. González W, Jiménez A, Madrigal G, Muñoz LM, Frongillo EA. Development and validation of measure of household food insecurity in urban Costa Rica confirms proposed generic questionnaire. J Nutr 2008; 138(3): 587-92. doi: 10.1093/jn/138.3.587. 